MATEC Web of Conferences 1, 00004 (2012)

DOI: $10.1051 /$ matecconf $/ 20120100004$

(C) Owned by the authors, published by EDP Sciences, 2012

\title{
Combined scale effects for effective brazing at low temperatures
}

\author{
D. Bartout ${ }^{1}$, J. Wilden ${ }^{2}$ \\ ${ }^{1}$ Joining and Coating Technology, Berlin Institute of Technology, Berlin, Germany \\ ${ }^{2}$ Faculty of Mechanical and Process Engineering, University of Applied Science Niederrhein, Germany
}

\begin{abstract}
In modern joining technology, the focus is on effective brazing and soldering of temperature sensitive materials. Here, as well as in diffusion welding processes the needed thermal energy is externally realized in the joint zone. This produces a heating of the whole joining parts, since in laminar joining the thermal energy is transported in interior by thermal conduction. An excess of critical temperatures or tolerable impact periods in wide parts of materials and respectively components is often not avoidable. This leads to thermal damages. In this point of view nanotechnology shows promising possibilities as scale effects and their resulting thermophysical effects such as melting temperature reduction and high diffusion rates can be used for providing a self-propagating high-temperature synthesis at room temperature. After ignition by an external energy source a self-propagating exothermic reaction is started. By producing a multilayer system with alternately arranged nanoscaled layers of e.g. Al and Ni the resulting thin foil can be used as heat source for melting the braze or solder material within the joining zone without any external preheating. Due to the high process velocities up to $30 \mathrm{~m} / \mathrm{s}$ and the local heat input significant thermal influences on the joined parts are not detectable.
\end{abstract}

\section{Introduction}

The fulfillment of the high requirements on modern technical components focuses on new joining technologies. Due to the temperature sensitivity of new high-strengthened materials and the challenges given by new aspects in economizing, such as light-weight constructions, conventional joining processes show several disadvantages which have to be overcome successfully. In this point of view nanotechnology plays an important role to meet the requirements as completely new properties are given by size effects and nanoadhesion. This will help to improve joining technologies and make them ready for upcoming challenges in the next decades. Main aspect in research and development within the Chair of Joining and Coating Technology at Berlin Institute of Technology is the application of such nanotechnologies and their given properties for joining processes such as brazing and soldering.

In the last years of intense research two possibilities had been ascertained to be very promising. One possibility is the use of SHS-Effect which is well known since the mid 60's of the 20th century. It is based on the use of negative enthalpy between different elements to start a self-propagating reaction. By applying these selfpropagating reactions in thin foils it is possible to provide the necessary energy for melting braze/solder material within the joining area without external heating. This will allow reducing thermal influences on the joined parts. Moreover, the thin and alternately arranged layers in a nanoscaled range allow high process speeds of about 30 $\mathrm{m} / \mathrm{s}$, so process efficiency is improved significantly. Altogether, the joining technology shows high potential for a wide application range, starting from classical mechanical engineering towards applications in electronics industry.

\section{State of the art}

Heat generation by exothermic reactions has been well known for many years. In a thermo-chemical exothermic reaction, chemical bond energy is converted to thermal energy. The enthalpy released can be estimated as difference of bond breaking enthalpy and bond formation enthalpy.

$$
\text { reactants } \Rightarrow \text { product }+ \text { energy }
$$

In the exothermic reaction, the total energy absorbed in bond breaking is less than the total energy released in bond making. This energy can be used for joining applications.

In the mid 60's of the 20th century the Russian researchers A.G. Merzhanov, I.P. Borovinskaya and V.M. Shikro discovered a way to start exothermic reactions without any liquid phase. First called "solid flame", the 
discovered effect was renamed later into "SelfPropagating High-Temperature Synthesis" and found its first industrial application in processing tantalumcarbides. The SHS-effect uses the released heat of formation while generating intermetallic phases form pure elements or compounds, respectively. Possible applications of this effect such as welding of refractory materials were published first in the former USSR. Since the beginning of the new millennium the number of released publications for welding using SHS raises constantly, for example welding of NiCrAlY-superalloys $[1,2]$ and iron based materials [3] using NiAl as SHS reactants. However, several disadvantages appear by handling the powders or pressed pellets and the necessity of preheating. Reproducibility is limited due to micrometer grain size and the undefined distribution and low diffusion rate of the reactants. A significant improvement can be achieved by establishing a high diffusion rate between the reactants in order to obtain a self-propagating exothermic reaction at room temperature. Two possible approaches are promising to achieve this goal. First one is minimizing the grain size towards a nanoscaled level as Dickenscheid reported [5]. This effect is based on the increased content of grain boundaries in this scale level and the involved higher diffusion rate as grain boundary diffusion is significantly higher than volume diffusion. Second approach is the reduction of melting-temperature in nanoscaled particles of films as reported in few classic papers [5-7]. The dependency of melting temperature Tm with regard to film thickness $d$ is shown as follows

$$
T_{m}(d)=T_{m} e^{-\frac{\sigma_{o} \cdot \vartheta}{L \cdot d}}
$$

Further, the temperature reduction depends on the surface tension $\sigma_{0}$, the molar volume in the solid phase $\vartheta$, the size of the grain $\mathrm{d}$ and the heat of fusion $\mathrm{L}$.

The combination of the described effects allows an igniting of the exothermic reaction in nano-structured multilayer foil or/and film at lower temperatures, e.g. in the $\mathrm{Ni}-\mathrm{Al}$ system at room temperature without further external preheating.

Table 1. Reaction properties between mirco structured $\mathrm{Al}$ and Ti powder [6].

\begin{tabular}{|c|c|c|c|c|}
\hline $\begin{array}{c}\text { Initial } \\
\text { temperature } \\
{[\mathrm{K}]}\end{array}$ & $\begin{array}{c}\text { Adiabatic } \\
\text { temperature } \\
{[\mathrm{K}]}\end{array}$ & Product & $\begin{array}{c}\text { Product } \\
\text { melting point } \\
{[\mathrm{K}]}\end{array}$ & $\begin{array}{c}\text { Combustion } \\
\text { regime }\end{array}$ \\
\hline 300 & 1518 & TiAl & 1732 & No Combustion \\
\hline 450 & 1599 & TiAl & 1732 & Spin regime \\
\hline 680 & 1732 & TiAl & 1732 & Steady state \\
\hline 800 & 1733 & $\mathrm{TiAl}+\mathrm{Al}+\mathrm{Ti}$ & 1732 & Steady state \\
\hline
\end{tabular}

During the formation of intermetallic phases, e.g. for Al$\mathrm{Ni}$, figure1, the negative bond enthalpy is released as shown in Table 1. As consequence of the energy difference, the heat is generated. One important advantage of SHS is the fact that the reaction takes place mainly in the solid state. The liquid phase may not be fully suppressed however molten material appears partially.
Table 2. Bond Enthalpy (T=273 K) of Al-Ni.

$\begin{array}{ll}\text { AlNi } & -59,2 \mathrm{KJ} / \mathrm{mol} \\ \text { AlNi3 } & -37,8 \mathrm{KJ} / \mathrm{mol} \\ \text { Al3Ni } & -37,6 \mathrm{KJ} / \mathrm{mol} \\ \text { Al3Ni2 } & -56,5 \mathrm{KJ} / \mathrm{mol} \\ \text { Al3Ni5 } & -46,0 \mathrm{KJ} / \mathrm{mol}\end{array}$

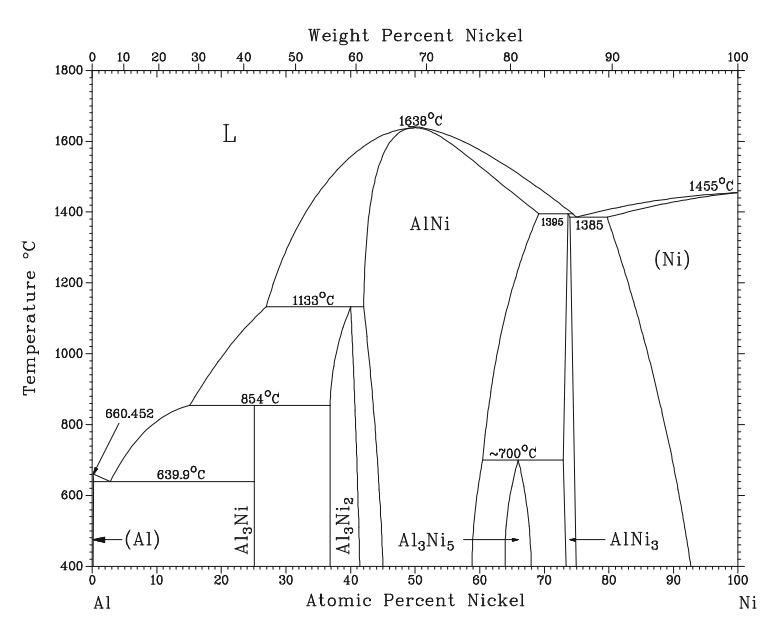

Fig.1. Binary phase diagram of Al-Ni [7].

After igniting by spark, flame, laser or other energy sources, the reaction propagates and releases the energy necessary for further propagation and melting of the joining materials such as braze or solder. Nowadays, first commercial products for the joining with nano-structured multilayer foils come to the market using the trade name Nanofoil ${ }^{\mathrm{TM}}$ and were launched by Reactive Nano Technologies, Inc. The trademark for the bonding process using Nanofoils ${ }^{\mathrm{TM}}$ is Nanobond ${ }^{\mathrm{TM}}$. These foils consist of alternately arranged nanostructured layers of $\mathrm{Al}$ and $\mathrm{Ni}$. By now, two different ways for production of such multilayer foils are known, magnetron sputtering and mechanical forming.

\section{Experiments and results}

Cr-Ni-steel joints were produced. The thickness of the AlNi- Nanofoil ${ }^{\mathrm{TM}}$ was $70 \mu \mathrm{m}$ and it was coated from both sides with $6 \mu \mathrm{m}$ Incusil-braze. The joining pressure was stepwise increased, the first step was $10 \mathrm{MPa}$. The joint strength increases up to a critical value of $26.2 \mathrm{MPa}$, where a joint strength of $1.21 \mathrm{MPa}$ for steel plates with a thickness of $0.5 \mathrm{~mm}$ and $0.89 \mathrm{MPa}$ for steel plates with a thickness of $1 \mathrm{~mm}$ was achieved. In figure 2 it can be seen that the joint partners were only partly wetted.
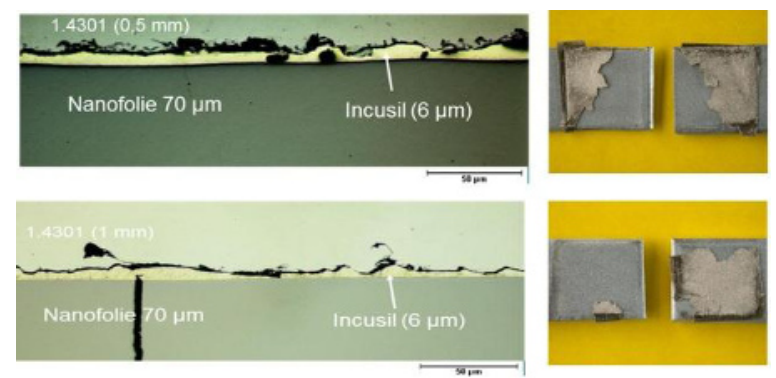

Fig. 2. 1.4301-1.4301-joint. 
We observed that under high joining pressure, a high tensile strength could be achieved. Under the effect of pressure, the flowability of the molten braze was improved. The gaps and fractures are filled better and thereby a better wetting of the joint partner is possible. When a critical value of the joining pressure is reached, the tensile strength doesn't increase anymore, figure 3. This critical value depends on the physical properties, the geometry of the foil, the braze and the component [8].

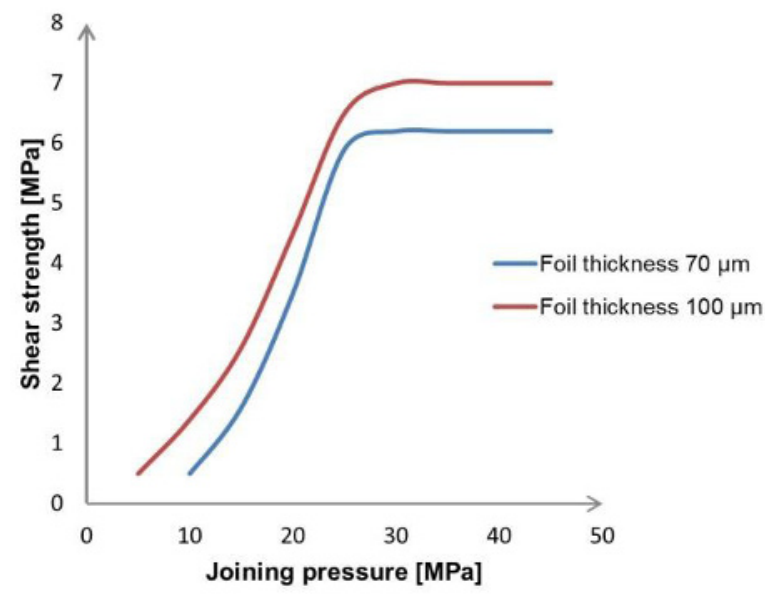

Fig. 3. Shear strength as a function of joining pressure.

The next used material was Titan. The $70 \mu \mathrm{m}$ nanofoil was coated with $6 \mu \mathrm{m}$ Incusil. In figure 4 , the variation joining pressure under normal atmosphere reaches his optimum at 26.2 MPa. With this pressure a strength of $7.03 \mathrm{MPa}$ was achieved. Increasing of pressure resulted in a decrease of joint strength.
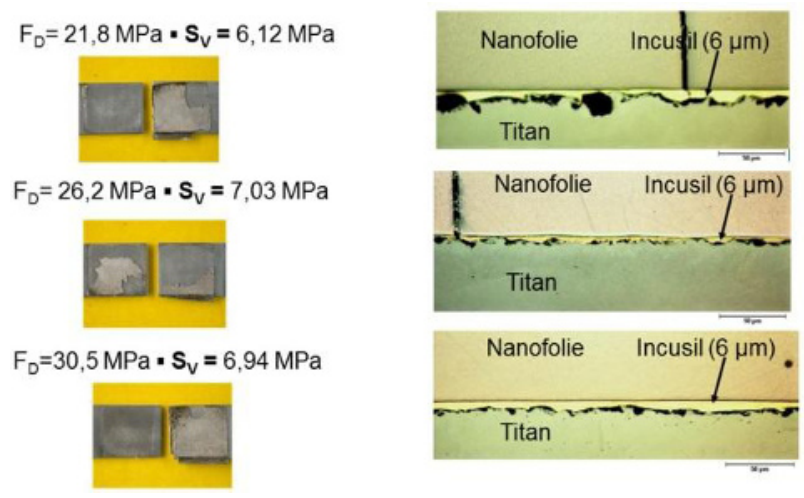

Fig. 4. Ti-Ti-joint under normal atmosphere.

Nickel coated materials were used to increase the joint strength, as nickel has a supporting effect relating to wetting. At first Al-Al-joints were produced. The used AlNi-Nanofoil $^{\mathrm{TM}}$ had a thickness of $40 \mu \mathrm{m}$ and was coated with $6 \mu \mathrm{m}$ tin-braze. Tin-brazes increase the strength and improve the brazeability. They have a good wetting capability and cause a high joining velocity. It can be seen in figure 5 that the Sn-braze has wet the Alsamples quite good. The achieved strength was over 5.8 $\mathrm{MPa}$. For $\mathrm{Cu}-\mathrm{Cu}$-joints also good strength was achieved (> 5.8 MPa), figure 6 .
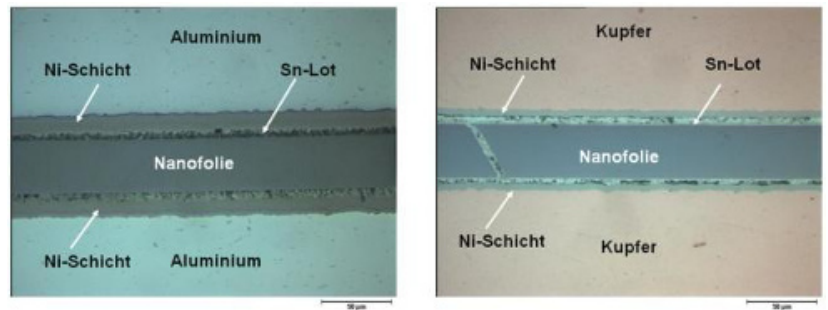

Fig. 5. Joint of nickel-plated Al-plates.

Fig. 6. Joint of nickel-plated Cu-plates.

While joining aluminium with copper a constant wetting took place as well, figure 7 . The Sn-braze has flown into the fractures which arose during the reaction process. This has a positive influence on the joint strength. In this joining experiment a strength of 6.61 $\mathrm{MPa}$ was achieved. The joint failed in the base material.

When the nanofoil reacts, it contracts because of compression, as well as during cooling, which comes from very high reaction temperatures. Both can lead to fractures in the foil as this process is constricted by the material surrounding the foil. Then the molten braze material flows into these fractures.
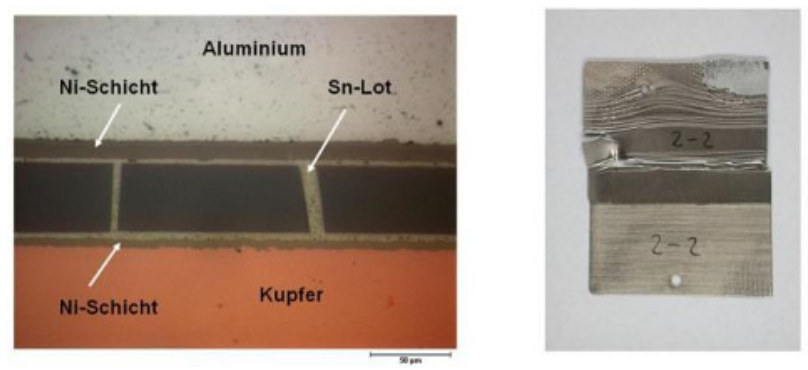

Fig. 7. Al-Cu-joint with a $40 \mu \mathrm{m}$ nanofoil and a Sn-braze.

\section{Conclusion}

The presented technology shows enormous potential in modern joining as the important aspect temperature sensitivity can be considered in an appropriate manner. By applying the Nanobond ${ }^{\mathrm{TM}}$ technology, the application range of brazing and soldering can be widened significantly. This technology provides the temperature, necessary for melting braze and solder material, within the joining area and works as a foil shaped energy source. High processing velocities of about $30 \mathrm{~m} / \mathrm{s}$ and therewith minimized local input of heat qualify this process for applications in conventional engineering as well as electronic industry. Further investigations will show the whole potential of this process. Next steps are the further improvement of wetting behavior in order to achieve higher tensile strengths.

\section{References}

1. D.F. Downey et al, Ion Implantation Technology, Prentice-Hall, (1993), pp. 65-67

2. Y. Wasserman, IEEE Trans-CPMT-A, Vol. 17, No. 3 (1995), pp. 346-351 
3. W. K. Shu, Proc 46th Electronic Components and Technology Conf, Orlando, FL, (1996), pp. 219-225.

4. P.H. Ralston, G.B. Hatch, U.S. Patent 3,803,038

5. W. Dickenscheid et al, Solid State Communications, Volume 79, Issue 8, (1991)

6. A.A. Borisov et al, Taylor \& Francis, New York, (2002)

7. Massalski et al., Binary alloy phase diagrams, ASM International, Materials Park, Ohio,(1996)

8. J. Wang, A. Duckham, S.J. Spey, E. Besnoin, O.M. Knio, T.P. Weihs, J. of Appl. Phys. 95, No.1, 248256 (2004) 